\title{
What happens after treatment? A systematic review of relapse, remission, and recovery in anorexia nervosa
}

\author{
Sahib S. Khalsa ${ }^{1,2^{*}}$, Larissa C. Portnoff ${ }^{3}$, Danyale McCurdy-McKinnon ${ }^{4}$ and Jamie D. Feusner ${ }^{5}$
}

\begin{abstract}
Background: Relapse after treatment for anorexia nervosa (AN) is a significant clinical problem. Given the level of chronicity, morbidity, and mortality experienced by this population, it is imperative to understand the driving forces behind apparently high relapse rates. However, there is a lack of consensus in the field on an operational definition of relapse, which hinders precise and reliable estimates of the severity of this issue. The primary goal of this paper was to review prior studies of AN addressing definitions of relapse, as well as relapse rates.

Methods: Data sources included PubMed and PsychINFO through March 19th, 2016. A systematic review was performed following the PRISMA guidelines. A total of $(N=27)$ peer-reviewed English language studies addressing relapse, remission, and recovery in AN were included.

Results: Definitions of relapse in AN as well as definitions of remission or recovery, on which relapse is predicated, varied substantially in the literature. Reported relapse rates ranged between 9 and 52\%, and tended to increase with increasing duration of follow-up. There was consensus that risk for relapse in persons with AN is especially high within the first year following treatment.

Discussion: Standardized definitions of relapse, as well as remission and recovery, are needed in AN to accelerate clinical and research progress. This should improve the ability of future longitudinal studies to identify clinical, demographic, and biological characteristics in AN that predict relapse versus resilience, and to comparatively evaluate relapse prevention strategies. We propose standardized criteria for relapse, remission, and recovery, for further consideration.
\end{abstract}

Keywords: Anorexia nervosa, Treatment, Outcome, Relapse, Remission, Recovery, Prevention, Eating disorder, Bulimia nervosa

\section{Plain English Summary}

Relapse occurs frequently in individuals receiving treatment for anorexia nervosa. However, there is no common agreement on how to define relapse. In this study, we reviewed previous studies of relapse, remission, and recovery following treatment for anorexia nervosa. We found that there were many different definitions for these terms, which resulted in different estimates of relapse rate. To understand what drives relapse it is

\footnotetext{
* Correspondence: skhalsa@laureateinstitute.org

'Laureate Institute for Brain Research, 6655 S Yale Ave, Tulsa, OK 74136, USA

${ }^{2}$ Oxley College of Health Sciences, The University of Tulsa, 1215 South Boulder Ave W, Tulsa, OK 74119, USA

Full list of author information is available at the end of the article
}

important to have a consistent definition across studies. To help this discussion we propose common criteria for relapse, remission, and recovery from anorexia nervosa.

\section{Background}

Anorexia nervosa (AN) is a serious psychiatric illness with amongst the highest mortality rates of any mental disorder-up to $18 \%$ in long-term follow-up studies [1$3]$. Most cases emerge during adolescence, and tend towards a protracted and chronic course $[4,5]$. In females, AN has a point prevalence of $0.3-1.0 \%$ and lifetime prevalence of $1.2-2.2 \%$ [6]. Treatment often succeeds in temporarily restoring weight, but AN individuals are at an exceedingly high risk for early relapse [7], and 
upwards of $50 \%$ relapse within the first year after successful hospital treatment [8]. The current lack of robust and reliable responses to treatment highlights the need for an improved ability to predict illness trajectories.

The primary focus of this review is on how relapse is defined following treatment for AN. Since relapse is typically defined relative to recovery and remission, we also consider how recovery and remission are defined. Pike has previously eloquently reviewed relapse, recovery, remission, and response in AN [8]. However, since then 11 studies have addressed this topic. The current review therefore incorporates these additional publications.

In preparing this review, a lack of clarity and uniformity with regard to how to best define relapse, recovery, and remission was apparent. This perspective is reinforced by a literature review of remission in eating disorders concluding that the definitions and associated rates vary considerably [9]. Fifteen years ago, a European collaboration of experts (COST Action B6) adapted definitions for relapse, recovery, partial and full remission, and recurrence from the depression literature to $\mathrm{AN}$ and bulimia nervosa (BN) [10]. Despite rigorous consensusbuilding and empirical testing of 233 inpatients with AN, these criteria have not been uniformly adopted by the field. To date there are no consensus guidelines available for clinicians or researchers at the professional or institutional level providing standardized operational definitions of relapse, recovery, or remission in AN. This is limiting. A greater consensus regarding the definition of these constructs would be of considerable benefit to clinicians, researchers, patients, and family members, by allowing all constituents to speak the same language.

We performed a focused review of the extant literature with the primary aim of examining how these terms have been defined, in order to improve definitions of relapse, recovery and remission in AN. Reviewing relapse rates was a secondary goal. We propose a set of standardized criteria for relapse, recovery, and remission from AN, which are internally cohesive and can facilitate longitudinal assessment by clinicians and researchers.

\section{Methods}

\section{Search and study selection}

We conducted a systematic qualitative review according to the PRISMA guidelines, searching the PubMed and PsychINFO databases. We used keywords for either "anorexia nervosa" or "eating disorders" along with "relapse," or "recovery," or "remission." We used an open search procedure. We also performed the same searches on Google Scholar to locate relevant articles that the other search methods possibly overlooked (none were identified). Our search covered articles that were published from 1975 to March 19th, 2016. Titles and abstracts were evaluated and full text was reviewed for relevant studies. References sections were screened manually for additional studies unidentified via database search.

\section{Eligibility criteria}

Participants had to meet ICD-10, DSM-III, IV, or 5 diagnostic criteria for AN for inclusion. Studies $(n=1)$ focusing on binge eating providing relevant information regarding relapse risk in AN or treatment outcomes of AN were also included. Studies examining BN and AN were included, but not those focused solely on $\mathrm{BN}$ ( $n=$ 2) (except for one [11] that provided treatment information pertinent to AN binge-purge (AN-BP) subtype). Omitted studies included those focused on unspecified eating disorders $(n=2)$, comorbid psychiatric disorders $(n=2)$, or those without clinical descriptions of relapse or recovery $(n=3)$. Non-English language articles were excluded $(n=6)$.

\section{Data review and study quality assessment}

Three authors (LCP, SSK, and JF) independently extracted the following data from the selected studies: first author, publication year, country, and whether the study was related to relapse, recovery, or remission. To evaluate the quality of the studies, we performed a systematic review of each article using the National Heart, Lung, and Blood Institute Study Quality Assessment Tool [12]. This tool provides a rating checklist for each study type. Three authors (LCP, DM, SSK) independently evaluated each study according to the rating checklist, and rendered a rating of "Good" or "Fair" or "Poor." Study quality was determined by comparing ratings agreement, with consensus required among reviewers. Discrepancies in study quality rating were reconciled via discussion of the individual items on the ratings checklist to arrive at consensus agreement on the quality indicator. Disagreements were resolved through discussion and consensus. There were no biases or poor methods identified that warranted exclusion from the review.

\section{Results}

We identified 27 studies meeting eligibility criteria (see Fig. 1). An overview of pertinent study characteristics and definitions of recovery/remission and relapse in AN are listed in Tables 1 and 2. Definitions of relapse were fundamental to understanding the reported rates in these studies. Our review revealed widely varied definitions of relapse and recovery/remission in AN. Definitions of recovery and remission are reviewed first since relapse is predicated upon them.

\section{Definitions of recovery and remission}

Recovery typically requires an extended period of time during which minimal or no criteria for the disorder are 


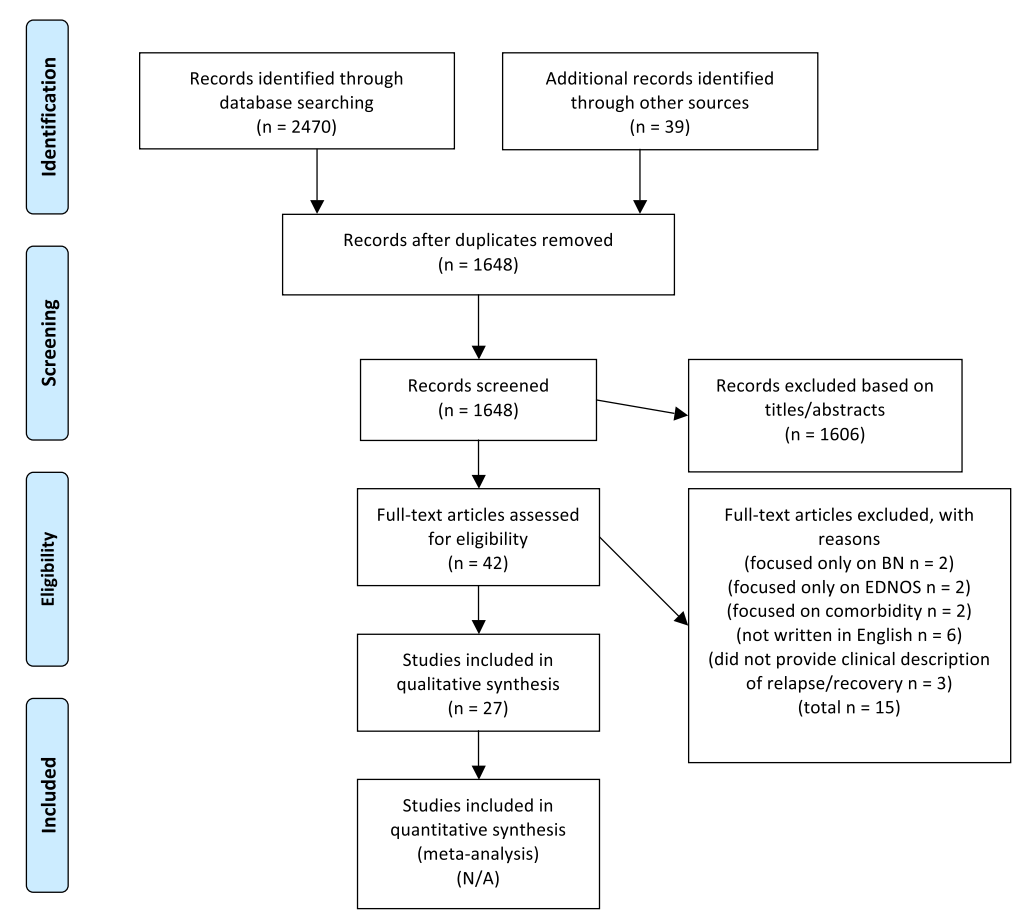

Fig. 1 Prisma diagram

met, whereas remission requires a shorter duration [13]. The literature can roughly be divided into articles that (1) define remission/recovery based solely on weight measurement, (2) define remission/recovery based solely on symptom reports, (3) define remission/recovery based solely on weight and symptom reports, i.e., diagnostic criteria available at the time. We briefly review these studies next (Table 1 lists studies providing definitions of partial remission, full remission, and recovery).

Several studies used body mass index (BMI) as the only criterion for recovery. Cutoffs included a BMI above 19 [14] or 20 [7, 15]. In contrast, some described remission based solely on psychiatric symptoms. In one, full remission was defined as an absence of all symptoms or only "residual symptoms" for at least 12 weeks, and partial remission was defined as a reduction of symptoms to a sub-diagnostic level for at least 12 weeks [16]. Adopted from the MacArthur guidelines for depression [13], Keel et al. [17] defined full remission as a Psychiatric Status Rating (PSR) score of $\leq 2$ for 8 weeks. Clausen [18] used the same score for 12 weeks, and defined partial remission as a PSR $\leq 3$ for 12 weeks.

Other articles described outcomes in terms of body weight and menstruation, using terminology such as "good," "intermediate," "poor," or "died" [19-22]. These criteria, or modifications of them, are often referred to as the "Morgan-Russell" criteria [19]. A later version specified remission as weight $\geq 85 \%$ of ideal body weight, regular menses, and no bingeing or purging behaviors
[23]. Modifying these criteria, recovery was later defined as not meeting AN DSM-IV-TR criteria for a minimum of 8 weeks [24].

Several proposed definitions included both weight and clinical symptoms. Pike [8] defined remission as $\geq 90 \%$ of ideal body weight, resumption of menses, absence of compensatory behaviors, and Eating Disorder Examination (EDE) [25] subscales within 2 standard deviations (SD) of normal. Recovery was defined as meeting remission criteria for at least 8 weeks. Strober et al. [4] defined full recovery as the absence of all criteria for at least 8 weeks, and partial recovery as a "good outcome" (weight within 15\% of average and normal menstruation) from the Morgan-Russell criteria [19]. Other studies did not have a duration criterion for the absence of symptoms but used the "good outcome" criteria to define recovery [20-22]. Stice's Eating Disorder Diagnostic Scale defined remission as $\mathrm{BMI} \geq 17.5$, regular menses, and no subthreshold or full threshold eating disorder [26, 27]. Martin [28] defined recovered as having a global rating scale of "excellent," meaning an individual was $>90 \%$ ideal weight, had regular menstruation, and normal eating and social patterns. Eckert et al. [29] defined "recovered" as within $15 \%$ of ideal body weight, cyclical menses, and no significant disturbance in eating or weight control behaviors or body image disturbance. Kordy et al. [10] defined full recovery for restricting AN as a BMI $>19$ and no extreme fear of weight gain for 12 months (plus no purging and no binges for 12 months 
Table 1 Definitions of recovery and remission, according to individual studies identified by the literature search

\begin{tabular}{|c|c|c|c|}
\hline Authors & Criteria & Duration & Study quality \\
\hline \multicolumn{4}{|l|}{ Definitions of Recovery } \\
\hline Martin, 1985 [28] & $\begin{array}{l}\text { "Excellent": > } 90 \% \text { of their ideal weight, regular } \\
\text { menstrual patterns, and eating and social patterns were } \\
\text { normal }\end{array}$ & Not specified & Fair \\
\hline Norring and Sohlberg, 1993 [34] & $\begin{array}{l}\text { "Well" defined as having no eating disorder diagnosis } \\
\text { or remnants of the weight and/or shape preoccupation }\end{array}$ & Not specified & Good \\
\hline Eckert et al., 1995 [29] & $\begin{array}{l}\geq 85 \% \text { of ideal body weight, cyclical menses, and no } \\
\text { significant disturbance in eating or weight control } \\
\text { behavior or body image disturbance }\end{array}$ & Not specified & Good \\
\hline Strober et al., 1997 [4] & $\begin{array}{l}\text { Free of all criterion symptoms of anorexia nervosa or } \\
\text { bulimia nervosa }\end{array}$ & 8 weeks & Good \\
\hline Fichter and Quadflieg, 1999 [21] & Outcome "good" defined using Morgan-Russell criteria & Not specified & Fair \\
\hline Pike, 1998 [8] & $\begin{array}{l}\geq 90 \% \text { of ideal body weight or } \mathrm{BMI} \geq 20 \text {, resumption of } \\
\text { menses, absence of binge eating or compensatory } \\
\text { behaviors, Eating Disorder Examination subscales within } \\
2 \text { SD of normal }\end{array}$ & 8 weeks & Fair \\
\hline Herzog, et al., 1999 [32] & $\begin{array}{l}\text { Absence of all symptoms or } 1-2 \text { residual symptoms- } \\
\text { Psychiatric Status Rating (PRS) score of } 1 \text { or } 2\end{array}$ & 8 weeks & Good \\
\hline Lowe et al., 2001 [22] & Outcome "good" defined using Morgan-Russell and PSR 1 & Not specified & Good \\
\hline Kordy et al., 2002 [10] & $\begin{array}{l}\text { AN-R: BMI > 19, no extreme fear of weight gain } \\
\text { AN-BP: BMI > 19, no extreme fear of weight gain, no } \\
\text { vomiting or laxative abuse, no binges }\end{array}$ & 12 months & Good \\
\hline Carter et al., 2004 [15] & BMI above 20 & Not specified & Good \\
\hline Walsh et al., 2006 [14] & BMl above 19 & No information & Good \\
\hline Eisler et al., 2007 [20] & Outcome "good" defined using Morgan-Russell criteria & Not specified & Good \\
\hline Bodell and Mayer, 2011 [24] & No DSM-IV criteria of AN & 8 weeks & Fair \\
\hline Bardone-Cone et al., 2010 [30] & $\begin{array}{l}\text { Full recovery: BMI } \geq 18.5 \text {, absence of binge-eating, } \\
\text { purging or fasting for at least } 3 \text { months, not meeting } \\
\text { criteria for current eating disorder, all EDE-Q subscales } \\
\text { within } 1 \text { SD of normal } \\
\text { Partial recovery: same as above, but not needing to } \\
\text { satisfy EDE-Q criterion }\end{array}$ & Not specified & Good \\
\hline Carter et al., 2012 [7] & $\begin{array}{l}\text { BMI of } 20 \text { and reported no more than one BP episode } \\
\text { before the end of treatment. }\end{array}$ & $\begin{array}{l}2 \text { weeks } \mathrm{BMI} \text { and no } \mathrm{BP} \\
\text { behaviors over the previous } \\
28 \text { days at the end of treatment }\end{array}$ & Good \\
\hline \multicolumn{4}{|l|}{ Definitions of Full Remission } \\
\hline Morgan and Hayward, 1988 [23] & $\begin{array}{l}\geq 85 \% \text { of ideal body weight, regular menses, and no } \\
\text { binge eating or purging behaviors }\end{array}$ & Not specified & Fair $^{a}$ \\
\hline Pike, 1998 [8] & $\begin{array}{l}\geq 90 \% \text { of ideal body weight or } \mathrm{BMI} \geq 20 \text {, resumption of } \\
\text { menses, absence of binge eating or compensatory } \\
\text { behaviors, EDE subscales within } 2 \mathrm{SD} \text { of normal }\end{array}$ & Not specified & Fair \\
\hline Stice et al., 2000 [27] & $\begin{array}{l}\text { BMI } \geq 17.5 \text {, regular menses, and no current } \\
\text { subthreshold or full threshold eating disorder }\end{array}$ & Not specified & Good $^{\text {a }}$ \\
\hline Kordy et al., 2002 [10] & $\begin{array}{l}\text { AN-R: BMI > 19, no extreme fear of weight gain } \\
\text { AN-BP: BMI > 19, no extreme fear of weight gain, no } \\
\text { vomiting or laxative abuse, no binges }\end{array}$ & 12 weeks & Good \\
\hline Keel et al., 2005 [17] & $\begin{array}{l}\text { Absence of all symptoms or } 1-2 \text { residual } \\
\text { symptoms-PSR score } \leq 2\end{array}$ & 8 weeks & Good \\
\hline Clausen, 2008 [18] & PSR score $\leq 2$ & 12 weeks & Good \\
\hline Helverskov et al., 2010 [16] & $\begin{array}{l}\text { Absence of all symptoms/1-2 Residual symptoms-PSR } \\
\text { score of } 1 \text { or } 2\end{array}$ & 12 weeks & Good \\
\hline
\end{tabular}


Table 1 Definitions of recovery and remission, according to individual studies identified by the literature search (Continued)

\begin{tabular}{lll}
\hline $\begin{array}{l}\text { Definitions of Partial Remission } \\
\text { Lowe et al., 2001 [22] }\end{array}$ & $\begin{array}{l}\text { Outcome "improved" defined using Morgan-Russell } \\
\text { criteria and PSR 2, 3, or 4 }\end{array}$ & Not specified \\
Kordy et al., 2002 [10] & AN-R: BMI > 17.5 & 4 weeks \\
& AN-BP: BMI > 17.5 in addition to $\leq 1$ binge per week & \\
and no vomiting or laxative abuse & Good \\
Clausen, 2008 [18] & PSR score $\leq 3$ & 12 weeks \\
Helverskov et al., 2010 [16] & PSR score of 3 & 12 weeks \\
\hline
\end{tabular}

${ }^{a}$ No NHLBI systematic criteria available to rate this study type; quality rating reflects consensus agreement between two rater assessments

Table 2 Definitions of relapse, according to individual studies identified by the literature search

\begin{tabular}{|c|c|c|c|}
\hline Authors & Criteria & Duration & Study quality \\
\hline \multicolumn{4}{|l|}{ Definitions of Relapse } \\
\hline Isager et al., 1985 [33] & $\begin{array}{l}\text { Loss of } \geq 15 \% \text { of weight acquired during course of } \\
\text { treatment (if resulting in weight } \leq 50 \mathrm{~kg} \text { ) }\end{array}$ & $\begin{array}{l}\text { Any point in time within a } 1 \text { year } \\
\text { period }\end{array}$ & Good \\
\hline Martin, 1985 [28] & $\begin{array}{l}\text { If the patient required further psychiatric treatment } \\
\text { after discharge during follow-up period }\end{array}$ & Not specified & Fair \\
\hline Norring and Sohlberg, 1993 [34] & "III" defined as having an eating disorder & Not specified & Good \\
\hline Eckert et al., 1995 [29] & $\begin{array}{l}\text { Loss of } \geq 15 \% \text { of average body weight (based on } \\
\text { Metropolitan Height-Weight Chart, 1959), after } \\
\text { achieving normal body weight }\end{array}$ & $\begin{array}{l}\text { Any point after achieving normal } \\
\text { weight during inpatient treatment } \\
\text { or the follow up period }\end{array}$ & Good \\
\hline Strober et al., 1997 [4] & $\begin{array}{l}\text { Full ("syndromal") relapse: weight }<85 \% \text { of ideal body } \\
\text { weight and recurrence of psychological symptoms } \\
\text { Partial ("subsyndromal") relapse: recurrence of psycho- } \\
\text { logical symptoms but } \geq 85 \% \text { of ideal body weight }\end{array}$ & Not specified & Good \\
\hline Fichter and Quadflieg, 1999 [21] & Outcome "poor" defined using Morgan-Russell criteria & Not specified & Fair \\
\hline Pike 1998 [8] & $\begin{array}{l}\text { BMI } \leq 18.5 \text { or weight } \leq 85 \% \text { of ideal body weight; a } \\
\text { minimum } 1 \text { SD increase on the Eating Disorder Evaluation; } \\
\text { loss of menstrual functioning if it has been previously } \\
\text { normal; increase in restriction leading to weight loss; } \\
\text { and possibly increased binge eating, compensatory } \\
\text { behavior, or associated medical problems }\end{array}$ & Not specified & Fair \\
\hline Herzog, et al., 1999 [32] & $\begin{array}{l}\text { Return to full criteria symptoms and/or Psychiatric } \\
\text { Status Rating (PSR) score of } 5 \text { or } 6\end{array}$ & $\begin{array}{l}8 \text { weeks following a state of full } \\
\text { recovery }\end{array}$ & Good \\
\hline Lowe et al., 2001 [22] & $\begin{array}{l}\text { Outcome "poor" defined using Morgan-Russell criteria } \\
\text { and PSR score of } 5 \text { or } 6\end{array}$ & Not specified & Good \\
\hline Kordy et al., 2002 [10] & $\begin{array}{l}\text { Change from partial or full remission to full syndrome } \\
\text { according to DSM-IV }\end{array}$ & Not specified & Good \\
\hline Carter, et al., 2004 [15] & $\begin{array}{l}\text { BMI below } 17.5 \text { and/or at least one episode of binge } \\
\text { eating/purging behavior per week }\end{array}$ & 3 consecutive months & Good \\
\hline Keel, et al., 2005 [17] & Return to full criteria symptoms and/or PSR score of 5 or 6 & Not specified & Good \\
\hline Walsh et al., 2006 [14] & $\begin{array}{l}\text { BMI below } 16.5 \text { for } 2 \text { consecutive weeks, or severe } \\
\text { medical complications, or risk of suicide, or development } \\
\text { of another psychiatric disorder requiring treatment }\end{array}$ & 2 consecutive weeks (low BMI) & Good \\
\hline Eisler et al., 2007 [20] & Outcome "poor" defined using Morgan-Russell criteria & Not specified & Good \\
\hline Clausen, 2008 [18] & PSR score $\geq 3$ & 3 months & Good \\
\hline Bodell and Mayer, 2011 [24] & $\begin{array}{l}\text { Poor outcome, BMI } \leq 18.5 \text { (using modified Morgan- } \\
\text { Russell criteria) }\end{array}$ & Not specified & Fair \\
\hline Helverskov, et al., 2010 [16] & Return to full criteria symptoms and/or PSR score of 5 or 6 & Not specified & Good \\
\hline Carter et al., 2012 [7] & $\begin{array}{l}\mathrm{BMI}<17.5 \text { or at least one episode of binge eating/ } \\
\text { purging behavior per week }\end{array}$ & 3 consecutive months & Good \\
\hline McFarlane et al., 2015 [31] & $\begin{array}{l}\text { AN: BMI }<18.5 \\
\text { AN-BP: average } 4 \text { episodes of bingeing and/or vomiting } \\
\text { per month, or BMI }<18.5\end{array}$ & 3 consecutive months & Good \\
\hline
\end{tabular}


for AN-BP). They defined full remission for both subtypes as meeting the same criteria for 3 months. Partial remission was a BMI $>17.5$ and $\leq 1$ binge per week and no vomiting or laxative abuse for 1 month in AN-BP. Another proposed definition of full recovery was a BMI $\geq 18.5$, absence of binging, purging, or fasting for at least 3 months, not meeting criteria for a current eating disorder, and all EDE-Questionnaire (EDE-Q) subscales within 1 SD of normal [30]. They defined partial recovery as the same without the EDE-Q criterion.

\section{Definitions of relapse}

Different definitions of relapse were identified (see Table 2). Some definitions were dependent on weight or BMI measures including: $\mathrm{BMI}<16.5$ for 2 weeks [14], and $\mathrm{BMI}<17.5[7,15]$ or $<18.5$ [31] for three consecutive months. Other definitions included $15 \%$ loss of average body weight after achieving normal body weight, either during the index hospitalization or any time during the 10-year follow-up period [29]. Strober et al. [4] similarly defined relapse as $<85 \%$ ideal body weight, which could occur post-discharge or post-recovery. Furthermore, relapse could be partial if the individual had recurrence of psychological symptoms but sustained $85 \%$ of ideal weight, or full relapse if both psychological symptoms returned and body weight dropped to less than $85 \%$. Several groups [19-22, 24] defined relapse as Morgan-Russell criteria of "poor" (BMI $\leq 18.5$ ).

Other definitions of relapse were dependent on psychiatric symptoms or a combination of psychiatric symptoms and weight changes. Kordy et al. [10] used a definition of change from DSM-IV partial or full remission to full syndrome. Clausen [18] defined relapse as $\mathrm{PSR} \geq 3$ or PSR $\leq 2$ after 3 months remission. Relapse has also been defined as meeting full syndrome criteria $(P S R \geq 5)$ after 8 weeks of remission $[17,32]$ and after 12 weeks of remission [16]. Pike's [8] more in-depth definition of relapse includes weight loss, EDE increase, medical issues, and a return of disordered eating, whereas Martin's [28] is the simplest, requiring only that an individual needs psychiatric intervention.

\section{Rates of Relapse}

Relapse rates of AN were highly variable ranging from a low of $9 \%$ to a high of $52 \%$ following treatment, with the majority of studies reporting rates greater than $25 \%$ [4, $7,10,14-18,21,22,24,28,29,32-34]$. Studies suggest that adolescents $[4,20,28]$ and individuals with restricting subtype AN $[7,29]$ have a lower likelihood of relapse. The first year is the most critical, with particular risk of relapse occurring as early as 3 months posttreatment $[4,7,15,32]$. Not surprisingly, those who recover fully have lower relapse rates $(9 \%)$ than those who only partially recover (35\%) [10]. Together, these results suggest that while most patients experience brief episodes of recovery, a large proportion relapse. Moreover, the risk is particularly high within the first year.

\section{Follow-Up Variability}

There was substantial variability in the literature for follow-up procedures. Initial evaluation time points ranged from 4 weeks to 17 months post-treatment [4, 7, $14,15,17,20,28,32,35]$. Some studies utilized only a single follow-up time point $[15,28]$, whereas others followed patients across multiple time points $[4,7,14$, $17,20,32,35]$. Some studies had regular follow-up visits (e.g., every 4 weeks [14], 3 months [7]), whereas others had irregularly spaced follow-ups (e.g., 2, 6 and 12 year follow up [35]).

Variable follow-up intervals could complicate estimations of relapse rates, since relapse rates can vary by duration of the study follow-up. According to this view, shorter follow-up durations might be associated with lower relapse rates than longer durations. We identified articles supporting this possibility. For example, relapse in a study measuring at 6 months was lower (9\% for fully recovered and $35 \%$ for partially recovered) [10] versus studies measuring at 1-year $(27-70 \%)$ [7, 14] (see Table 3). Relapse rates also varied by remission criteria, with stricter remission criteria displaying lower relapse rates than less stringent criteria. This is evidenced by two 10-year longitudinal studies. Eckert and colleagues [29] reported higher relapse rates (42\%) with less stringent relapse criteria and Strober and colleagues [4] reported lower relapse rates $(29.5 \%)$ with stricter relapse criteria.

\section{Discussion}

The main finding of this review is that there are almost as many definitions of relapse, remission, and recovery as there are studies of them. To help rectify this state of affairs, we suggest that the eating disorders research and clinical communities evaluate, test, and ultimately adopt standardized definitions for relapse, remission, and recovery. Depression [13], bipolar disorder [36], and schizophrenia [37] researchers already utilize standardized definitions of these constructs. Consensus guidelines for response, partial response, remission, recovery, and relapse in obsessive compulsive disorder were also recently proposed [38]. However, we could identify no such definitions for AN across organizational websites, including: the Academy for Eating Disorders, Eating Disorders Research Society, National Eating Disorders Association, and the European Council on Eating Disorders.

Standardizing how relapse and recovery are defined in research could substantially improve our understanding 


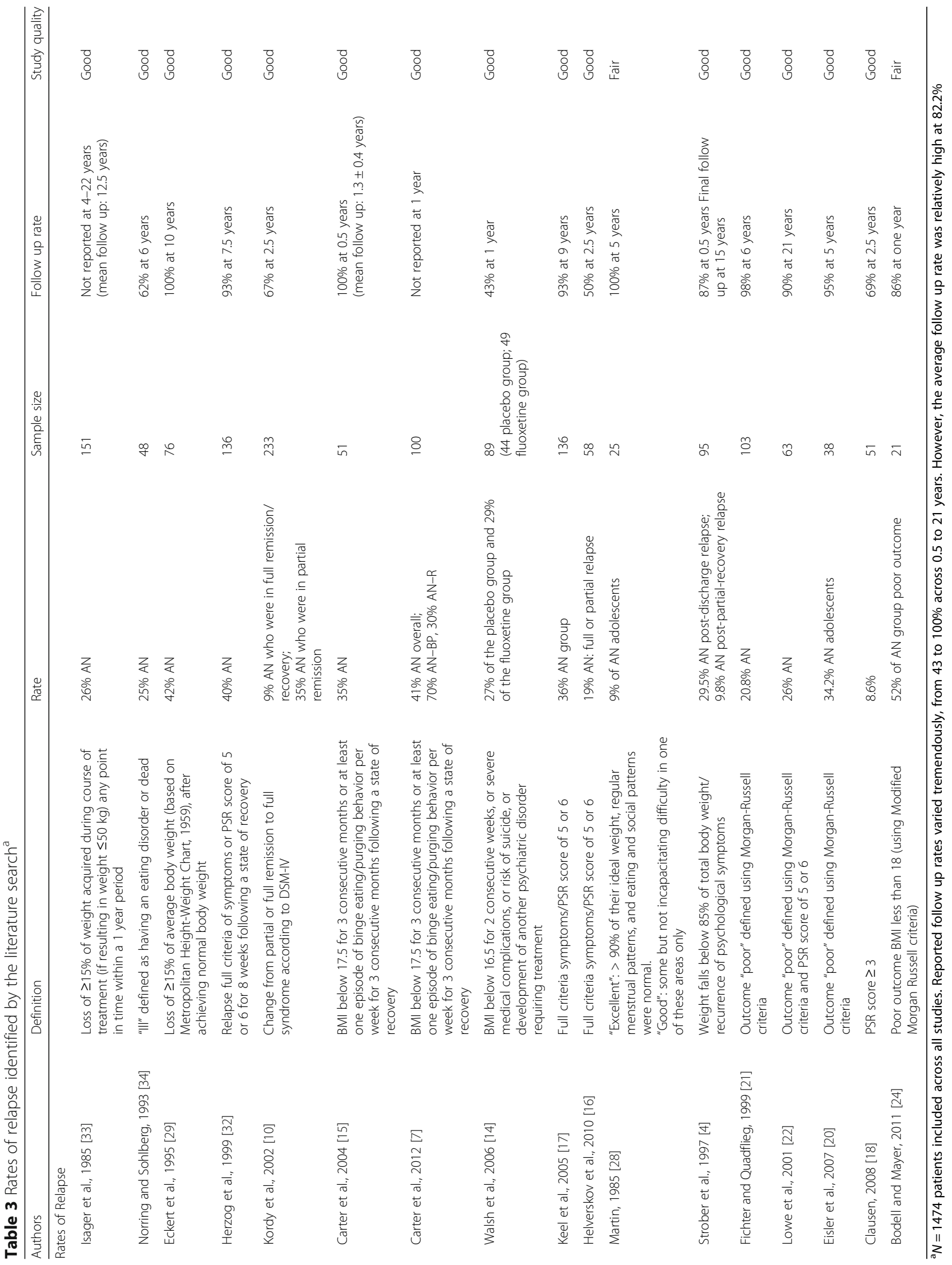


of the pathophysiology of AN and help ground studies of efficacy and effectiveness, as argued previously [39, 40]. Consensus would increase the quality of metaanalytic studies. It would facilitate multi-site comparisons, which are necessary to improve statistical power for studying this relatively rare condition. Precise and consistent terminology would also enhance communication amongst researchers, clinicians, and caregivers.

We propose a unifying framework with potential definitions for recovery, remission, and relapse to energize the discussion (see Fig. 2). These definitions are internally logical, consistent, and conducive to longitudinal assessment of AN. We advocate the adoption of standardized definitions for partial and full recovery and partial and full relapse. DSM-5 defines partial and full remission, but not partial or full recovery, and the duration requirement is vague ("a sustained period") [41]. We propose that definitions of relapse in AN should encompass both clinical symptoms and signs such as BMI measures, ${ }^{1}$ as has been proposed for definitions of recovery [42], to more comprehensively capture the disorder. Importantly, our suggested criteria for recovery, remission, and relapse include objective measures (BMI; observable behaviors of restricting, binging, and purging), subjective measures (fear of gaining weight, disturbance of body image), standardized ratings (EDE), and specific durations of follow-up $(1,3,6$, and 12 months) that are conducive to utilization across both clinical and research settings (see Fig. 3).

It is worth noting that the proposed approach shares certain similarities with previous efforts to identify patterns of recovery in AN. For example, the Psychiatric Status Rating (PSR) scale represented a single six-item clinician rating based on DSM-III criteria [43]. Lower scores on this scale, such as a 1, indicated 'usual self' or the absence of meeting diagnostic criteria, whereas higher scores, such as a 6 , indicated presence of 'definite criteria, severe.' The PSR is similar to our proposed

\begin{tabular}{|c|c|c|c|c|c|}
\hline Illness status & BMI criteria & Symptoms & Behaviors & Scales & Duration \\
\hline Full recovery & $\begin{array}{l}\text { BMI } \geq 20 \\
\text { or } \\
\geq 90 \% \text { ideal body } \\
\text { weight }\end{array}$ & $\begin{array}{l}\text { No significant } \\
\text { fear of gaining } \\
\text { weight or } \\
\text { disturbance in } \\
\text { body image }\end{array}$ & $\begin{array}{l}\text { No restricting, } \\
\text { bingeing, or } \\
\text { purging }\end{array}$ & $\begin{array}{l}\text { EDE within } \\
1 \text { SD of } \\
\text { normal }\end{array}$ & 12 months \\
\hline $\begin{array}{l}\text { Partial } \\
\text { recovery }\end{array}$ & $\begin{array}{l}\mathrm{BMI} \geq 19 \\
\text { or } \\
\geq 85 \% \text { ideal body } \\
\text { weight }\end{array}$ & $\begin{array}{l}\text { No significant } \\
\text { fear of gaining } \\
\text { weight or } \\
\text { disturbance in } \\
\text { body image }\end{array}$ & $\begin{array}{l}\text { No restricting, } \\
\text { bingeing, or } \\
\text { purging }\end{array}$ & $\begin{array}{l}\text { EDE within } \\
1.5 \mathrm{SD} \text { of } \\
\text { normal }\end{array}$ & 6 months \\
\hline Full remission & $\begin{array}{l}\text { BMI } \geq 19 \\
\text { or } \\
\geq 85 \% \text { ideal body } \\
\text { weight }\end{array}$ & $\begin{array}{l}\text { Fear of gaining } \\
\text { weight or } \\
\text { disturbance in } \\
\text { body image } \\
\text { present }\end{array}$ & $\begin{array}{l}\text { No restricting, } \\
\text { bingeing, or } \\
\text { purging }\end{array}$ & $\begin{array}{l}\text { EDE within } \\
2 \text { SD of } \\
\text { normal }\end{array}$ & 3 months \\
\hline $\begin{array}{l}\text { Partial } \\
\text { remission }\end{array}$ & $\begin{array}{l}\text { BMI } \geq 18.5 \\
\text { or } \\
\geq 85 \% \text { ideal body } \\
\text { weight }\end{array}$ & $\begin{array}{l}\text { Fear of gaining } \\
\text { weight or } \\
\text { disturbance in } \\
\text { body image } \\
\text { present }\end{array}$ & $\begin{array}{l}\text { No restricting, } \\
\text { bingeing, or } \\
\text { purging }\end{array}$ & $\begin{array}{l}\text { EDE within } \\
2 \text { SD of } \\
\text { normal }\end{array}$ & 1 month \\
\hline Partial relapse & $\begin{array}{l}\text { BMI } \leq 18.5 \\
\text { or } \\
\leq 85 \% \text { ideal body } \\
\text { weight }\end{array}$ & $\begin{array}{l}\text { Significant fear } \\
\text { of gaining } \\
\text { weight or } \\
\text { disturbance in } \\
\text { body image }\end{array}$ & $\begin{array}{l}\text { Restricting, } \\
\text { bingeing, or } \\
\text { purging } \\
\text { present }\end{array}$ & $\begin{array}{l}E D E \geq 2 S D \\
\text { of normal }\end{array}$ & 1 month \\
\hline Full relapse & $\begin{array}{l}\text { BMI } \leq 18.5 \\
\text { or } \\
\leq 85 \% \text { ideal body } \\
\text { weight }\end{array}$ & $\begin{array}{l}\text { Significant fear } \\
\text { of gaining } \\
\text { weight or } \\
\text { disturbance in } \\
\text { body image }\end{array}$ & $\begin{array}{l}\text { Significant } \\
\text { restricting, } \\
\text { bingeing, or } \\
\text { purging } \\
\text { present }\end{array}$ & $\begin{array}{l}E D E \geq 2 S D \\
\text { of normal }\end{array}$ & 3 months \\
\hline
\end{tabular}

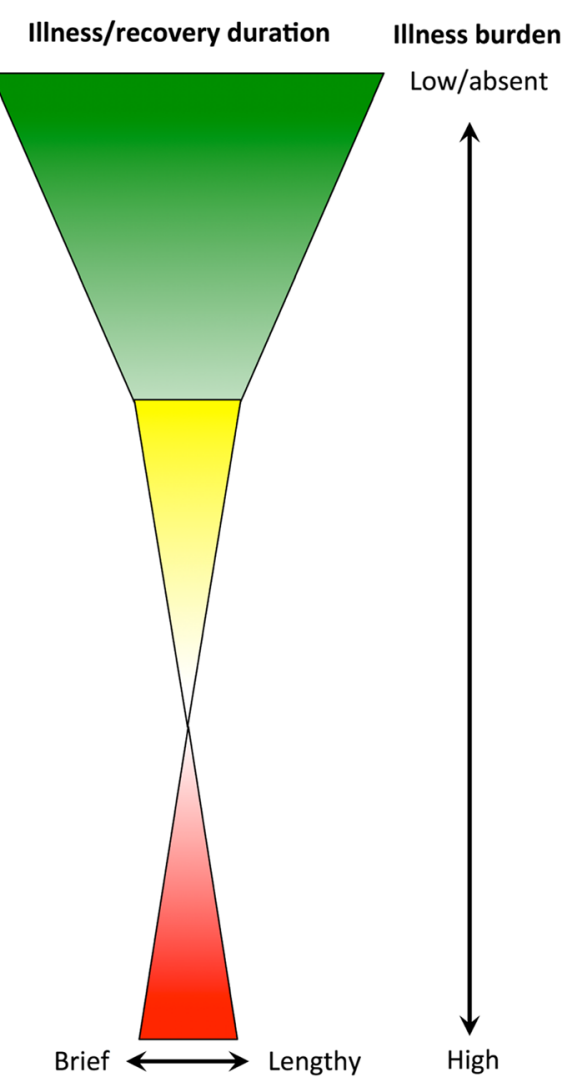

Fig. 2 Proposed standardized definitions of relapse, remission, and recovery. These standardized definitions were synthesized from the different criteria for relapse, remission, and recovery in individual studies identified by our systematic review. We include a graphical representation of these definitions as a useful heuristic tool for conceptualizing the major transition points (relapse in red, remission in yellow, recovery in green) while at the same time underscoring the continuum of pathology existing within each stage. Note 1: since weight and height normally increase until age 20 in pediatric and adolescent populations, age- and gender- adjusted BMI percentiles for determining expected body weight (EBW) are more appropriate in these subgroups, as demonstrated by [52]. Note 2: determination of ideal body weight is complex, and subject to consideration of racial, ethnic, demographic, and cultural factors [53]. Note 3: Symptoms and behaviors are discrete variables, which are rated/ascertained by the clinician based on all available clinical information 


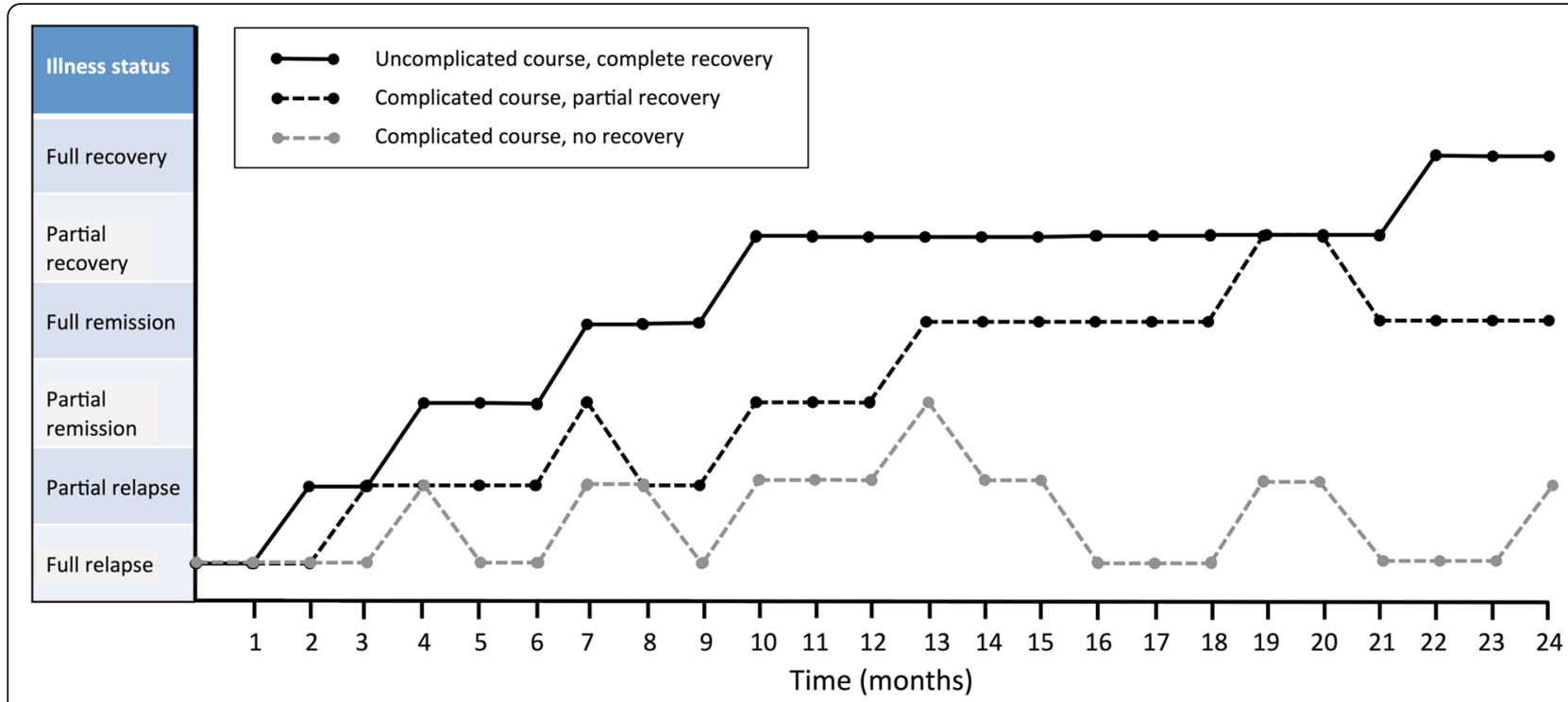

Fig. 3 IIIness trajectories across a 2 year time period for three hypothetical individuals with AN exhibiting different illness courses. One individual with an uncomplicated course shows a consistent transition from full relapse to full remission to full recovery. Another individual shows a complicated course marked by partial remission, partial relapse, and partial recovery, followed by a decline to full remission. A third individual shows a complicated course with no recovery marked by intermittent bouts of full relapse punctuated by partial relapse and partial remission. For an analogous depiction of illness trajectory based on actual patients, see Kordy et al., [10]

approach in the sense that both require clinician ratings, and both load upon features of AN that are relevant to diagnostic criteria in terms of weight status, symptom burden, and ongoing behaviors. However, our proposed criteria diverge principally with respect to (1) a focus on defining stages of relapse, remission, and recovery, (2) reliance upon a standardized and clinically validated interview (EDE), and (3) utilization of terminology (partial or full relapse, partial or full remission, partial or full recovery) that are transparent and can be utilized uniformly with patients, caregivers, and clinicians. Our EDE cutoff selection for partial relapse (greater than or equal to $2 \mathrm{SD}$ below normal) is also consistent with the 'cutoff point a,' which as previously suggested by Jacobsen et al. [44], represents a conservative and stringent approach to determining clinically significant changes.

Due to the highest risk of relapse being in the first year $[4,17,20,32,33]$ and relapse often occurring as early as 3 months post-treatment $[4,7,15,32]$, we recommend that longitudinal studies conduct follow up assessments no less than every 3 months for the first year, and every 6 months thereafter for longer studies. Without standardized definitions, a refined understanding of the specific outcomes posed by putative risk factors, and guidance on measurement, we are in danger of adding more variability to this literature. Clinically, standardized definitions for relapse, remission and recovery, combined with consistent monitoring, would help provide consistent and relevant feedback to patients and family members regarding their level of risk.
There are several important limitations to consider when interpreting this review. There is an inherent difficulty identifying the true risk factors predicting AN relapse given the disparate definitions of relapse and recovery provided to date, potentially giving our review the appearance that it is challenged by a lack of synthesis. We argue that this challenge is precisely what future studies would overcome by adopting and adhering to one set of standards. Secondly, our interpretations are restricted to the somewhat obvious conclusions that AN is: (1) characterized by high relapse rates, (2) that relapse rates increase with follow-up lengths, and (3) there are few reliable predictors. While it seems nearly impossible to glean generalizations from such heterogeneous findings, this highlights the necessity for consensus and standardized definitions. It is important to emphasize that while the current review has focused on AN, based in part, on our own research efforts, we believe that similar consensus standards are needed for other eating disorders such as bulimia nervosa, binge eating disorder, and unspecified eating disorder. Although advancing such definitions are beyond the scope of our qualitative review, we hope that highlighting this disparity will provoke further discussion and progress. Finally, adding a meta-analytic approach could derive 'quantitative data' characterizing outcomes, but at this point, would not be additively informative given the aforementioned limitations. This approach would be useful for a future analysis of aggregated studies using uniform definitions. 


\section{The value of reaching consensus}

It will be important to carefully consider the value of reaching consensus on definitions of relapse, remission, and recovery, who will benefit, and how a consensus would be best achieved. It is hard to imagine a lasting consensus without the support of eating disorder organizations. These include organizations which are scienceoriented (e.g., Eating Disorder Research Society (EDRS) [45], Academy for Eating Disorders (AED) [46] European Council on Eating Disorders (ECED) [47]), clinician-oriented (AED, National Eating Disorders Association (NEDA) [48], and International Association of Eating Disorders Professionals (IAEDP) [49]), and patient and caregiver-oriented (e.g., Families Empowered and Supporting Treatment of Eating Disorders (FEAST) [50], National Alliance on Mental Illness (NAMI) [51], AED, and NEDA).

It is also necessary to prospectively consider the potential challenges to achieving a consensus. In this regard, the highly interdisciplinary perspectives required in the research and treatment of eating disorders (pediatrics, family medicine, psychiatry, psychology, nutrition and dietetics, social work, licensed therapy and counseling, and nursing) results in complex and often diverging multifactorial models, which risks a fracturing of consensus regarding these conditions.

Concrete suggestions for harmonizing this discussion include (1) the development of conference symposia, (2) cross-organization workgroups or task forces, and (3) the generation of consensus statements focused on the topic. Other practical considerations include feasibility assessments. For example, follow up frequency will always be of concern, and conducting monthly, quarterly, and perhaps even bi-annual follow-ups requires resources that may be infeasible for certain research groups. We would argue that follow up assessment occurring at any frequency should use a standardized approach that is comparable to other laboratories. Inperson assessments might be supplemented by phone interviews, and/or the remote collection of collateral information from family members, and we observed evidence of this pragmatic approach in the literature surveyed in this paper.

\section{Conclusion}

The heterogeneity and severity of AN presentation poses challenges to understanding why relapse occurs, and how to prevent it. We posit that the eating disorders community will benefit from considering, testing, and adopting standardized definitions for relapse, remission, and recovery. To galvanize this movement, we have attempted to provide a unifying framework with internally logical and consistent definitions. This framework is conducive to longitudinal clinical and research assessment, not only for AN, but for bulimia nervosa, binge eating disorder, unspecified eating disorder, and other eating disorders. Without consensus, uncertainty and variability in the reported recovery, remission, and relapse rates will persist. Standardizing definitions in AN is a critical first step in identifying at-risk individuals, and can ultimately advance the development and evaluation of treatments for this lifethreatening illness.

\section{Endnotes}

${ }^{1}$ Since weight and height normally increase until age 20 in pediatric and adolescent populations, age- and gender- adjusted BMI percentiles for determining expected body weight (EBW) are more appropriate in these subgroups (see Le Grange et al., [52]).

\section{Abbreviations \\ AN: Anorexia nervosa; BMl: Body mass index; BN: Bulimia nervosa; \\ DSM: Diagnostic and statistical manual of mental disorders; EDE: Eating Disorder Examination; EDNOS: Eating disorder not otherwise specified; PSR: Psychiatric Status Rating}

\section{Acknowledgments}

We would like to thank Michael Strober for helpful discussions and comments on the manuscript, Courtney Sheen for administrative support with performing the literature review, and Francesca Morfini for assistance with manuscript retrieval.

\section{Funding}

This research was supported by NIMH grant numbers R01MH093535 and R01MH105662 to Jamie D. Feusner, and by NIMH grant number

K23MH112949 to Sahib S. Khalsa. Dr. Khalsa also received support from The William K. Warren Foundation and a NARSAD Young Investigator Award.

\section{Availability of data and materials}

This review paper was developed on previously published data that can be obtained from the original source studies.

\section{Authors' contributions}

JDF, LCP and SSK conceived the research idea, SSK, LCP, DM and JDF drafted and edited the manuscript. All authors have read and approved the final manuscript before submission.

\section{Competing interests}

The authors declare that they have no competing interests.

Consent for publication

Not applicable

Ethics approval and consent to participate

Not applicable

\section{Publisher's Note}

Springer Nature remains neutral with regard to jurisdictional claims in published maps and institutional affiliations.

\section{Author details}

${ }^{1}$ Laureate Institute for Brain Research, 6655 S Yale Ave, Tulsa, OK 74136, USA. ${ }^{2}$ Oxley College of Health Sciences, The University of Tulsa, 1215 South Boulder Ave W, Tulsa, OK 74119, USA. ㄹDepartment of Clinical Psychology, Teachers College, Columbia University, 525 W 120th St, New York, NY 10027, USA. ${ }^{4}$ Department of Pediatrics, The University of California Los Angeles, 757 Westwood Plaza, Los Angeles, CA 90095, USA. ${ }^{5}$ Department of Psychiatry and Biobehavioral Sciences, The University of California Los Angeles, Semel Institute of Neuroscience and Human Behavior, 760 Westwood Plaza, Los Angeles, CA 90024, USA. 


\section{Received: 28 January 2017 Accepted: 19 April 2017}

Published online: 14 June 2017

\section{References}

1. Harris EC, Barraclough B. Excess mortality of mental disorder. Br J Psychiatry. 1998;173:11-53.

2. Sullivan PF. Mortality in anorexia nervosa. Am J Psychiatry. 1995;152(7):1073-4.

3. Arcelus J, Mitchell AJ, Wales J, Nielsen S. Mortality rates in patients with anorexia nervosa and other eating disorders. A meta-analysis of 36 studies. Arch Gen Psychiatry. 2011;68(7):724-31.

4. Strober M, Freeman R, Morrell W. The long-term course of severe anorexia nervosa in adolescents: survival analysis of recovery, relapse, and outcome predictors over 10-15 years in a prospective study. Int J Eat Disord. 1997; 22(4):339-60.

5. Steinhausen HC, Grigoroiu-Serbanescu M, Boyadjieva S, Neumarker KJ, Winkler Metzke C. Course and predictors of rehospitalization in adolescent anorexia nervosa in a multisite study. Int J Eat Disord. 2008;41(1):29-36.

6. Smink FR, van Hoeken D, Hoek HW. Epidemiology of eating disorders: incidence, prevalence and mortality rates. Curr Psychiatry Rep. 2012;14(4): 406-14

7. Carter JC, Mercer-Lynn KB, Norwood SJ, Bewell-Weiss CV, Crosby RD, Woodside DB, Olmsted MP. A prospective study of predictors of relapse in anorexia nervosa: implications for relapse prevention. Psychiatry Res. 2012; 200(2-3):518-23.

8. Pike KM. Long-term course of anorexia nervosa: response, relapse, remission, and recovery. Clin Psychol Rev. 1998;18(4):447-75.

9. Ackard DM, Richter SA, Egan AM, Cronemeyer CL. What does remission tell us about women with eating disorders? Investigating applications of various remission definitions and their associations with quality of life. J Psychosom Res. 2014;76(1):12-8.

10. Kordy H, Kramer B, Palmer RL, Papezova H, Pellet J, Richard M, et al. Remission, recovery, relapse, and recurrence in eating disorders: Conceptualization and illustration of a validation strategy. J Clin Psychol. 2002;58(7):833-46.

11. Fichter MM, Kruger R, Rief W, Holland R, Dohne J. Fluvoxamine in prevention of relapse in bulimia nervosa: effects on eating-specific psychopathology. J Clin Psychopharmacol. 1996;16(1):9-18.

12. National Heart, Lung, and Blood Institute (NHLBI) Study Quality Assessment Tool [cited 2017 March 15]; Available from: https://www.nhlbi.nih.gov/ health-pro/guidelines/in-develop/cardiovascular-risk-reduction/tools/.

13. Frank E, Prien RF, Jarrett RB, Keller MB, Kupfer DJ, Lavori PW, et al. Conceptualization and rationale for consensus definitions of terms in major depressive disorder. Remission, recovery, relapse, and recurrence. Arch Gen Psychiatry. 1991:48(9):851-5.

14. Walsh BT, Kaplan AS, Attia E, Olmsted M, Parides M, Carter JC, et al. Fluoxetine after weight restoration in anorexia nervosa: a randomized controlled trial. JAMA. 2006;295(22):2605-12.

15. Carter JC, Blackmore E, Sutandar-Pinnock K, Woodside DB. Relapse in anorexia nervosa: a survival analysis. Psychol Med. 2004;34(4):671-9.

16. Helverskov JL, Clausen L, Mors O, Frydenberg M, Thomsen PH, Rokkedal K. Trans-diagnostic outcome of eating disorders: A 30-month follow-up study of 629 patients. Eur Eat Disord Rev. 2010;18(6):453-63.

17. Keel PK, Dorer DJ, Franko DL, Jackson SC, Herzog DB. Postremission predictors of relapse in women with eating disorders. Am J Psychiatry. 2005; 162(12):2263-8

18. Clausen L. Time to remission for eating disorder patients: a 2(1/2)-year followup study of outcome and predictors. Nord J Psychiatry. 2008;62(2):151-9.

19. Morgan HG, Russell GFM. Value of family background and clinical features as predictors fo long-term outcome in anorexia-nervosa - 4-year follow-up study of 41 patients. Psychol Med. 1975;5(4):355-71.

20. Eisler I, Simic M, Russell GF, Dare C. A randomised controlled treatment trial of two forms of family therapy in adolescent anorexia nervosa: a five-year follow-up. J Child Psychol Psychiatry. 2007;48(6):552-60.

21. Fichter MM, Quadflieg N. Six-year course and outcome of anorexia nervosa. Int J Eat Disord. 1999;26(4):359-85.

22. Lowe B, Zipfel S, Buchholz C, Dupont Y, Reas DL, Herzog W. Long-term outcome of anorexia nervosa in a prospective 21-year follow-up study. Psychol Med. 2001;31(5):881-90.

23. Morgan $\mathrm{HG}$, Hayward AE. Clinical assessment of anorexia nervosa. The Morgan-Russell outcome assessment schedule. Br J Psychiatry. 1988;152(3): 367-71.
24. Bodell LP, Mayer LE. Percent body fat is a risk factor for relapse in anorexia nervosa: a replication study. Int J Eat Disord. 2011:44(2):118-23.

25. Fairburn CG, Cooper Z. The Eating Disorder Examination. In: Fairburn CG, Wilson GT, editors. Binge eating: Nature, assessment and treatment. New York: Guilford Press; 1993.

26. Stice $E$, Fisher M, Martinez E. Eating disorder diagnostic scale: additional evidence of reliability and validity. Psychol Assess. 2004;16(1):60-71.

27. Stice E, Telch CF, Rizvi SL. Development and validation of the Eating Disorder Diagnostic Scale: a brief self-report measure of anorexia, bulimia, and binge-eating disorder. Psychol Assess. 2000;12(2):123-31.

28. Martin FE. The treatment and outcome of anorexia nervosa in adolescents: a prospective study and five year follow-up. J Psychiatr Res. 1985;19(2-3): 509-14

29. Eckert ED, Halmi KA, Marchi P, Grove W, Crosby R. Ten-year follow-up of anorexia nervosa: clinical course and outcome. Psychol Med. 1995;25(1):143-56.

30. Bardone-Cone AM, Harney MB, Maldonado CR, Lawson MA, Robinson DP, Smith $\mathrm{R}$, Tosh A. Defining recovery from an eating disorder: Conceptualization, validation, and examination of psychosocial functioning and psychiatric comorbidity. Behav Res Ther. 2010;48(3):194-202.

31. McFarlane T, MacDonald DE, Trottier K, Olmsted MP. The effectiveness of an individualized form of day hospital treatment. Eat Disord. 2015:23(3): $191-205$.

32. Herzog DB, Dorer DJ, Keel PK, Selwyn SE, Ekeblad ER, Flores AT, et al. Recovery and relapse in anorexia and bulimia nervosa: a 7.5-year follow-up study. J Am Acad Child Adolesc Psychiatry. 1999;38(7):829-37.

33. Isager $\mathrm{T}$, Brinch $\mathrm{M}$, Kreiner $\mathrm{S}$, Tolstrup K. Death and relapse in anorexia nervosa: survival analysis of 151 cases. J Psychiatr Res. 1985;19(2-3):515-21.

34. Norring CE, Sohlberg SS. Outcome, recovery, relapse and mortality across six years in patients with clinical eating disorders. Acta Psychiatr Scand. 1993; 87(6):437-44.

35. Fichter MM, Quadflieg N, Hedlund S. Twelve-year course and outcome predictors of anorexia nervosa. Int J Eat Disord. 2006:39(2):87-100.

36. Tohen M, Frank E, Bowden CL, Colom F, Ghaemi SN, Yatham LN, et al. The International Society for Bipolar Disorders (ISBD) Task Force report on the nomenclature of course and outcome in bipolar disorders. Bipolar Disord. 2009:11(5):453-73.

37. Andreasen NC, Carpenter Jr WT, Kane JM, Lasser RA, Marder SR, Weinberger DR. Remission in schizophrenia: proposed criteria and rationale for consensus. Am J Psychiatry. 2005;162(3):441-9.

38. Mataix-Cols D, de la Cruz LF, Nordsletten AE, Lenhard F, Isomura K, Simpson HB. Towards an international expert consensus for defining treatment response, remission, recovery and relapse in obsessive-compulsive disorder. World Psychiatry. 2016;15(1):80-1.

39. Noordenbos $\mathrm{G}$. When have eating disordered patients recovered and what do the DSM-IV criteria tell about recovery? Eat Disord. 2011;19(3):234-45.

40. Von Holle A, Pinheiro AP, Thornton LM, Klump KL, Berrettini WH, Brandt $\mathrm{H}_{\text {, }}$ et al. Temporal patterns of recovery across eating disorder subtypes. Aust $\mathrm{N}$ Z J Psychiatry. 2008;42(2):108-17.

41. American Psychiatric Association. Diagnostic and statistical manual of mental disorders: DSM-5. 5th ed. Washington, DC: American Psychiatric Association; 2013.

42. Couturier J, Lock J. What is remission in adolescent anorexia nervosa? A review of various conceptualizations and quantitative analysis. Int J Eat Disord. 2006;39(3):175-83.

43. Herzog DB, Sacks NR, Keller MB, Lavori PW, von Ranson KB, Gray HM. Patterns and predictors of recovery in anorexia nervosa and bulimia nervosa. J Am Acad Child Adolesc Psychiatry. 1993;32(4):835-42.

44. Jacobson NS, Roberts LJ, Berns SB, McGlinchey JB. Methods for defining and determining the clinical significance of treatment effects: description, application, and alternatives. J Consult Clin Psychol. 1999; 67(3):300-7.

45. Eating Disorders Research Society. [cited 2017 March 15] Available from: http://edresearchsociety.org/.

46. Academy for Eating Disorders. [cited 2017 March 15] Available from: http:// www.aedweb.org.

47. European Council on Eating Disorders. [cited 2017 March 15] Available from: http://www.eced.co.uk/.

48. National Eating Disorders Association. [cited 2017 March 15] Available from: http://www.nationaleatingdisorders.org/.

49. The International Association of Eating Disorders Professionals. [cited 2017 March 15] Available from: http://www.iaedp.com/. 
50. Families Empowered and Supporting Treatment of Eating Disorders. [cited 2017 March 15] Available from: http://www.feast-ed.org.

51. National Alliance on Mental Illness. [cited 2017 March 15] Available from: http://www.nami.org/.

52. Le Grange D, Doyle PM, Swanson SA, Ludwig K, Glunz C, Kreipe RE. Calculation of expected body weight in adolescents with eating disorders. Pediatrics. 2012;129(2):e438-46.

53. Caprio S, Daniels SR, Drewnowski A, Kaufman FR, Palinkas LA, Rosenbloom AL, Schwimmer JB. Influence of race, ethnicity, and culture on childhood obesity: implications for prevention and treatment: a consensus statement of Shaping America's Health and the Obesity Society. Diabetes Care. 2008; 31(11):2211-21.

Submit your next manuscript to BioMed Central and we will help you at every step:

- We accept pre-submission inquiries

- Our selector tool helps you to find the most relevant journal

- We provide round the clock customer support

- Convenient online submission

- Thorough peer review

- Inclusion in PubMed and all major indexing services

- Maximum visibility for your research

Submit your manuscript at www.biomedcentral.com/submit
Biomed Central 